Cite this article as: BMJ, doi:10.1136/bmj.39133.668681.BE (published 23 March 2007)

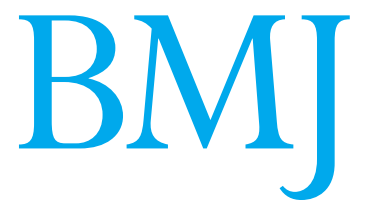

RESEARCH

\title{
Pre-endoscopy serological testing for coeliac disease: evaluation of a clinical decision tool
}

\author{
Andrew D Hopper, gastroenterology specialist registrar, ${ }^{1}$ Simon S Cross, reader in pathology and honorary \\ consultant in pathology, , ${ }^{3}$ David P Hurlstone, consultant gastroenterologist, ${ }^{1}$ Mark E McAlindon, consultant \\ gastroenterologist, ${ }^{1}$ Alan J Lobo, consultant gastroenterologist, ${ }^{1}$ Marios Hadjivassiliou, consultant \\ neurologist, ${ }^{4}$ Marion E Sloan, general practitioner, ${ }^{5}$ Simon Dixon, senior lecturer in health economics, ${ }^{2}$ David \\ S Sanders, consultant gastroenterologist ${ }^{1}$
}

Department of Gastroenterology, Royal Hallamshire Hospital, Sheffield

${ }^{2}$ Health Economics and Decision Science (HEDS), University of Sheffield, Sheffield

${ }^{3}$ Section of Oncology and Pathology, Division of Genomic Medicine, University of Sheffield Medical School, Sheffield

${ }^{4}$ Department of Neurology, Royal Hallamshire Hospital

${ }^{5}$ Surgery, 29 Blackstock Road, Sheffield S14 1AB

Correspondence to: A D Hopper, 15 Nairn Street, Sheffield S10 1UL andydhopper@aol.com

doi: 10.1136/bmj.39133.668681.BE

\section{ABSTRACT}

Objective To determine an effective diagnostic method of detecting all cases of coeliac disease in patients referred for gastroscopy without performing routine duodenal biopsy.

Design An initial retrospective cohort of patients attending for gastroscopy was analysed to derive a clinical decision tool that could increase the detection of coeliac disease without performing routine duodenal biopsy. The tool incorporated serology (measuring antibodies to tissue transglutaminase) and stratifying patients according to their referral symptoms (patients were classified as having a "high risk" or "low risk" of coeliac disease). The decision tool was then tested on a second cohort of patients attending for gastroscopy. In the second cohort all patients had a routine duodenal biopsy and serology performed.

Setting Teaching hospital in Sheffield.

Participants 2000 consecutive adult patients referred for gastroscopy recruited prospectively.

Main outcome measure Evaluation of a clinical decision tool using patients' referral symptoms, tissue

transglutaminase antibody results, and duodenal biopsy results.

Results No cases of coeliac disease were missed by the pre-endoscopy testing algorithm. The prevalence of coeliac disease in patients attending for endoscopy was $3.9 \%$ (77/2000, $95 \%$ confidence interval $3.1 \%$ to $4.8 \%)$. The prevalence in the high risk and low risk groups was $9.6 \%(71 / 739,7.7 \%$ to $12.0 \%)$ and $0.5 \%(6 / 1261,0.2 \%$ to $1.0 \%)$. The prevalence of coeliac disease in patients who were negative for tissue transglutaminase antibody was $0.4 \%(7 / 2000)$. The sensitivity, specificity, positive predictive value, and negative predictive value for a positive antibody result to diagnose coeliac disease was $90.9 \%, 90.9 \%, 28.6 \%$, and $99.6 \%$, respectively.

Evaluation of the clinical decision tool gave a sensitivity, specificity, positive predictive value, and negative predictive value of $100 \%, 60.8 \%, 9.3 \%$, and $100 \%$, respectively.

Conclusions Pre-endoscopy serological testing in combination with biopsy of high risk cases detected all cases of coeliac disease. The use of this decision tool may enable the endoscopist to target patients who need a duodenal biopsy.

\section{INTRODUCTION}

Coeliac disease is a common chronic inflammatory bowel condition encountered by doctors. Serological screening in healthy volunteers around the world has estimated the prevalence at $0.5-1.0 \%{ }^{1-7} \mathrm{~A}$ recent metaanalysis indicated that the ratio of known to undiagnosed cases of coeliac disease was 1:7. ${ }^{6}$ This suggests a failure in case finding for this disease. ${ }^{69}$ The median age for diagnosis of coeliac disease in adults is between the fourth and fifth decade. ${ }^{10-12}$ The median delay in diagnosis ranges from 4.9 to 11 years. ${ }^{10-12}$

Patients with adult coeliac disease usually present with diarrhoea, weight loss, or symptoms that suggest malabsorption or anaemia. This type of coeliac disease is known as the classic (typical) form. The disease may not always be recognised however because of the insidious nature of its presentation, and many visits to hospital may be needed before diagnosis. ${ }^{13}$ Patients can also have the silent or atypical form of disease. These patients may present with non-specific abdominal pain, ${ }^{14}$ oesophageal reflux, ${ }^{1516}$ osteoporosis, cryptogenic hypertransaminasaemia, insulin dependent diabetes mellitus, ${ }^{17}$ or neurological symptoms. ${ }^{5618}$ Untreated coeliac disease is associated with high morbidity and increased mortality. ${ }^{1920}$

Although the presentation of patients with coeliac disease may be protean, serological markers are a cheap and non-invasive method for clinicians in primary care and secondary care to identify patients with this disease. The positive and negative predictive value of combining the measurement of IgA antibodies to tissue transglutaminase and IgA endomysial antibodies has been reported to be greater than $96 \%{ }^{21}$ Current serological testing for coeliac disease involves the use of one or both of these antibodies, depending on local practice. ${ }^{22}$ However, the internationally accepted "gold standard" diagnostic test for coeliac disease is the demonstration of villous atrophy on a duodenal biopsy. ${ }^{2324}$ Such biopsies are graded 
histologically according to the modified Marsh criteria and reflect the pathological progression (histologically) towards coeliac disease. Marsh grade 0 is normal duodenal mucosa, grade 1 is the presence of a raised intraepithelial lymphocyte count, and grade 2 is raised intraepithelial lymphocytes and crypt hyperplasia. Marsh grade 1 and grade 2 lesions are considered to be early changes in patients who are likely to develop coeliac disease. Marsh grade 3 is raised intraepithelial lymphocytes and crypt hyperplasia with progression of the inflammation to villous atrophy. Marsh grade 3 is subdivided into Marsh 3a-partial villous atrophy, $3 \mathrm{~b}$ - subtotal villous atrophy, and $3 \mathrm{c}$ - total villous atrophy ${ }^{2526}$ The presence of a Marsh 3 lesion (villous atrophy) on duodenal biopsy together with a positive antibody profile is currently internationally accepted as coeliac disease, although antibody negative coeliac disease does exist. ${ }^{2324}$ This may occur if patients are IgA deficient (and cannot generate IgA tissue transglutaminase antibodies or endomysial antibodies), but it can also happen in patients who have normal total IgA immunoglobulin concentrations. Such patients are classed as having coeliac disease if they have villous atrophy on duodenal biopsy and the appropriate human leucocyte antigen pattern (HLA DQ2 or HLA DQ8). They should also have symptoms suggestive of coeliac disease that respond to a gluten-free diet and show a corresponding improvement in histology. ${ }^{2324}$ A previous European multicentre series reported that antibody negative coeliac disease accounted for $6.4 \%$ (8 of 126) of all cases of coeliac disease. ${ }^{27}$

A duodenal biopsy can be taken from any patient referred for gastroscopy. We and others have reported that $13.6 \%$ of patients later diagnosed with coeliac disease had had a gastroscopy within the previous five years but no duodenal biopsy had been taken. ${ }^{10}$ This may be because of sole reliance on endoscopic features for recognising coeliac disease, even though such features are only $50-87.5 \%$ sensitive for detecting this disease. ${ }^{28}$ Higher levels of detection are thought to correlate with endoscopic experience and the severity of villous atrophy. In addition, inter-rater reliability is poor. ${ }^{28}$ Because of the limitations of endoscopy, antibody negative coeliac disease, and delays in diagnosis, many centres around the world suggest or recommend routine duodenal biopsy. In clinical practice, however, this policy varies greatly, and reported rates of duodenal biopsy range from $30.9 \%$ to $74 \%{ }^{29-32}$ The reported prevalence of coeliac disease when taking a routine duodenal biopsy ranges from $1.0 \%$ to $5.2 \%{ }^{33-42}$ However, prevalence depends greatly on the population studied. Since the advent of tissue transglutaminase and endomysial antibodies, the practice of routine duodenal biopsy has not been fully evaluated in the context of referrals from primary care.

We devised and evaluated a clinical decision tool that used a combination of pre-endoscopy serological testing (for tissue transglutaminase antibodies) and assessment of symptoms to identify patients with coeliac disease. This decision tool might help increase the detection of coeliac disease in patients attending for gastroscopy without the need to perform routine duodenal biopsy.

\section{METHODS}

Retrospective analysis and creation of a clinical decision tool

From January 2003 to January 2004 our centre performed 5979 gastroscopies. We analysed the data from 1464 unselected patients who had both a gastroscopy and duodenal biopsy. On the basis of this retrospective data, the prevalence of new cases of coeliac disease identified in patients referred for endoscopy was $4.2 \%$ (61 of 1464).

We assessed the indications for referral in these unselected patients and whether the biopsy findings indicated coeliac disease. We categorised patients with indications of weight loss, anaemia, or diarrhoea as having a "high risk" for coeliac disease. In routine clinical practice, such patients should have a duodenal biopsy taken as per British Society of Gastroenterology guidelines. ${ }^{434}$ Anaemia was defined as a haemoglobin concentration of less than $120 \mathrm{~g} / \mathrm{l}$ in female patients and less than $130 \mathrm{~g} / \mathrm{l}$ in male patients; diarrhoea was defined as a bowel frequency of more than three times a day (both definitions as suggested by British Society of Gastroenterology guidelines). ${ }^{434}$ Patients were deemed as having lost weight if this was stipulated in the referral letter from their general practitioner and confirmed by the patient at gastroscopy. The remaining patients (whose symptoms were atypical for coeliac disease) were categorised as having a "low risk." Symptoms classified as low risk include all other indications for gastroscopy, such as abdominal pain, reflux, dyspepsia, vomiting or nausea, and chest pain. Of the 1464 patients analysed who had gastroscopy and a duodenal biopsy, $1085(74.1 \%)$ were high risk and $379(25.9 \%)$ were low risk.

In this retrospective group, tissue transglutaminase antibody titre was part of the antibody profile performed in 109 patients. Eighty nine of the 109 patients $(81.7 \%)$ were at high risk and $20(18.3 \%)$ were at low risk of coeliac disease. Tissue transglutaminase antibody testing was performed in these patients because the investigating doctor considered coeliac disease to be a possible cause of their symptoms before gastroscopy. Eighteen of the 109 patients $(16.5 \%)$ had coeliac disease, two of whom were negative for tissue transglutaminase antibodies. Nineteen of the 109 patients were positive for tissue transglutaminase antibodies-16 had coeliac disease but three had a normal duodenal biopsy. The sensitivity, specificity, positive predictive value, and negative predictive value for tissue transglutaminase antibodies in the detection of coeliac disease were $94.1 \%, 96.7 \%, 84.2 \%$, and $97.8 \%$. The two antibody negative patients with coeliac disease both had high risk referral symptoms. When we combined the referral indication of high risk with positive tissue transglutaminase antibody results the sensitivity for diagnosing coeliac disease was 100\% (95\% confidence interval $82.4 \%$ to $100 \%$ ). 


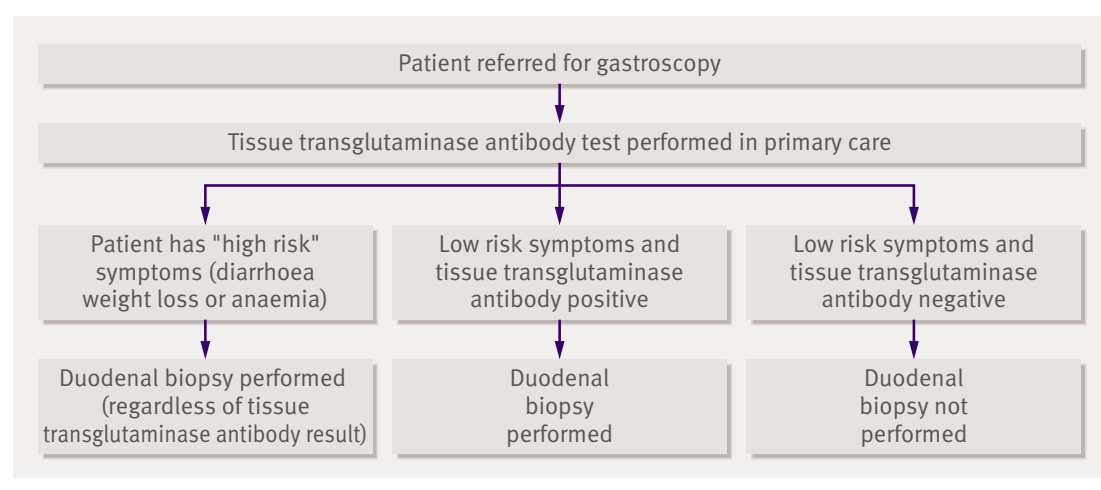

Fig 1 | Suggested clinical decision tool of pre-endoscopy serological testing and identification of high risk patients to target patients who need a duodenal biopsy

On the basis of these data, we devised a clinical decision tool that might obviate the need to perform routine duodenal biopsy but still detect unrecognised coeliac disease in patients referred for gastroscopy. We proposed that combining pre-endoscopy serological testing (using tissue transglutaminase antibodies) with identification of high risk patients would allow us to target patients who need a duodenal biopsy (fig 1).

\section{Prospective evaluation of clinical decision tool}

We recruited patients from a single endoscopy department at the Royal Hallamshire Hospital, Sheffield. This centre serves a population of around 250000 and carries out 5000-6000 gastroscopies annually. The patients had been referred by their general practitioner for either gastroscopy or a consultation and gastroscopy. A single endoscopist recruited participants for the evaluation study (second cohort) during a 26 month period (January 2004 to April 2006). The department of medical gastroenterology currently performs duodenal biopsy as part of the endoscopic examination. We classified all patients according to the referral information into high risk and low risk groups. At gastroscopy, we confirmed the symptoms described in the referral letter by questioning the patient directly and obtained patient consent. Quadrantic biopsies were taken from the second part of the duodenum in all patients. We also took a blood sample which was analysed for IgA tissue transglutaminase antibodies. We excluded patients if they had a known diagnosis of coeliac disease, coagulopathy (international normalised ratio $>1.3$ or platelets $<80 \times 10^{9} /$ litre), or active gastrointestinal bleeding, or if a suspected carcinoma was identified during the examination $(n=220)$.

Duodenal biopsy specimens were fixed in buffered formalin and embedded in paraffin wax. Standard 3 $\mu \mathrm{m}$ thick sections at three levels were stained with haematoxylin and eosin and reported routinely. We graded villous atrophy according to the modified Marsh criteria.

We used a commercially available enzyme linked immunosorbent assay to measure $\mathrm{IgA}$ antibodies to tissue transglutaminase. A titre of $>15 \mathrm{U} / \mathrm{ml}$ was taken as positive (as recommended by the manufacturer).

We classed patients with villous atrophy and a negative antibody profile as having antibody negative coeliac disease only if they fulfilled previously described criteria. $^{2324546}$ To support such a diagnosis, we excluded alternative causes of villous atrophy (such as infection with Giardia or Helicobacter pylori) or selective IgA deficiency). In addition, all cases of coeliac disease and any equivocal cases were then reviewed by a gastrointestinal histopathologist who independently assessed the consistency of sampling and reporting.

\section{Data analysis}

We used SPSS version 10.0 to analyse the data; $95 \%$ confidence intervals were calculated by the Wilson method. We determined the sample size needed for our prospective study in consultation with the Sheffield University statistical services unit at the start of the study. For our prospective study to give a sensitivity of $100 \%$ (like our retrospective data), but with a narrower confidence width, our sample size needed to be 2000. This would give a 95\% confidence interval of $98.8 \%$ to $100 \%$ (a width of $1.2 \%$ ).

\section{RESULTS}

We recruited 2000 patients (1167 (58.3\%) women, mean age 55.8, range 16-94). No patients refused to participate in the study. We categorised 739 patients into the high risk group and 1261 into the low risk group according to their referral indications (fig 2). In total, 77 patients were newly diagnosed with coeliac disease. The independent gastrointestinal histopathology review confirmed consistency in both sampling and reporting of duodenal biopsies. No diagnoses were changed as a result of this review.

The prevalence of coeliac disease in all patients attending for gastroscopy was 3.9\% (77/2000, 95\% confidence interval $3.1 \%$ to $4.8 \%$ ). In the high risk group prevalence was $9.6 \%$ (71/739, $7.7 \%$ to $12.0 \%)$.

The prevalence of tissue transglutaminase antibody negative coeliac disease was $0.4 \%(7 / 2000,0.2 \%$ to $0.7 \%$ ). All cases of antibody negative coeliac disease occurred in the high risk group (fig 2). Only one of these seven antibody negative patients had selective IgA deficiency. Antibody negative coeliac disease accounted for $9.1 \%(7 / 77,4.5 \%$ to $17.6 \%)$ of cases within this cohort.

The prevalence of coeliac disease in the low risk group was $0.5 \%$ (6/1261, $0.2 \%$ to $1.0 \%$ ). Symptoms (abdominal pain, reflux, and irritable bowel syndrome) improved in these six patients when they ate a gluten-free diet (duration of follow-up three to 18 months).

Using the tissue transglutaminase antibody test alone to diagnose coeliac disease gave a sensitivity, specificity, positive predictive value, and negative predictive value of $90.9 \%, 90.9 \%, 28.6 \%$, and $99.6 \%$. 


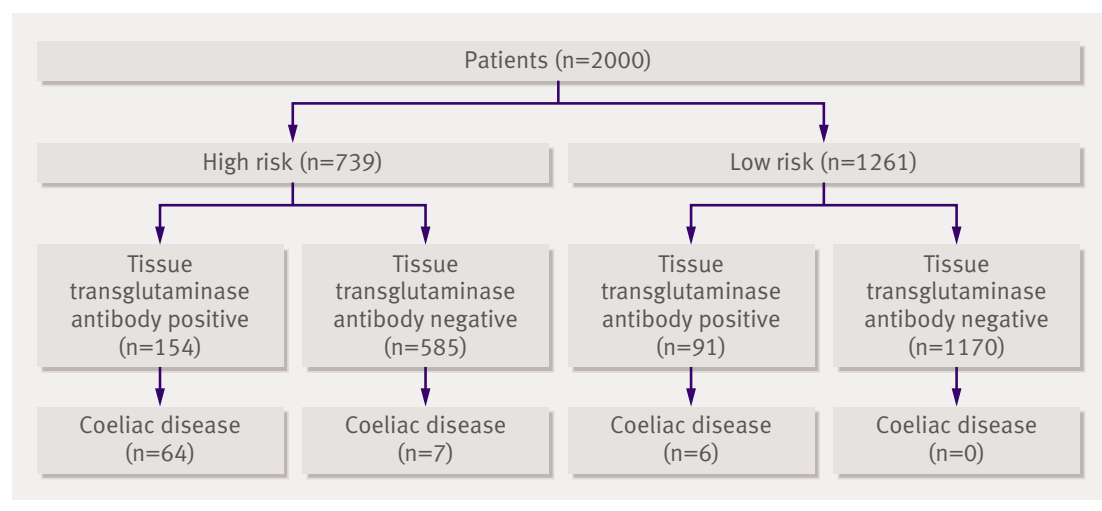

Fig 2 | Patients' serological and histopathology results according to high and low risk of coeliac disease based on current British Society of Gastroenterology guidelines, which are probably not widely available in primary care. We therefore think the most pragmatic approach would be serological testing for all patients referred for gastroscopy.

The exact antibody test needed is debateable. Many centres recommend a two step approach (tissue transglutaminase antibodies first, followed by endomysial antibodies in patients with positive results). ${ }^{47} \mathrm{How}^{-}$ ever, for logistical reasons this approach may not be applicable to pre-endoscopy testing - the complete antibody profile may not be available by the time the patient arrives for gastroscopy. We found that using tissue transglutaminase antibodies alone was adequate and cheap and that no cases of coeliac disease were overlooked. Testing for tissue transglutaminase antibodies is the cheapest and most accurate option, as the immunofluorescence method used to detect endomysial antibodies is subjective and uses expensive tissue as the substrate (monkey oesophagus or umbilical cord). ${ }^{47}$

The advent of point of care testing for tissue transglutaminase antibodies may influence clinical practice. ${ }^{484}$ Preliminary reports suggest that sensitivity and specificity are comparable to those seen for serology. ${ }^{4849}$ Point of care testing might shift the onus to conduct this test from general practitioners to the endoscopy unit, where the test could perhaps be done immediately before endoscopy. This might be a more effective way of using the decision tool in the future. However, in the United Kingdom because of practice based commissioning (for primary care), many general practitioners may choose to adopt this policy as a cost effective approach.

\section{Cost effectiveness}

We anticipate that our decision tool will be cost effective. In our study, the decision tool reduced the work load associated with processing and reporting duodenal biopsies to $41.5 \%$ of that of the routine biopsy method. Earlier diagnosis might result in fewer consultations in primary care and possibly fewer referrals to secondary care,$^{13}$ which would also reduce healthcare costs. In addition, a prompt diagnosis would improve the quality of life for patients with coeliac disease at an earlier stage and potentially save money by delaying onset of the complications of coeliac disease.

\section{Conclusion}

In this data set, pre-endoscopy serological testing combined with biopsy of high risk cases had a sensitivity of $100 \%$. The use of this clinical decision tool may enable the endoscopist to target patients who need a duodenal biopsy. This strategy might increase the detection rate of coeliac disease.

Contributors: $\mathrm{ADH}$ helped design the study; collect, analyse, and interpret data; draft the article; and recruit patients. ADH is guarantor. SD helped analyse and interpret the data and review the final version of the manuscript. DPH, MEMCA, AJL, MES, and MH helped recruit patients, analyse and interpret the data, and review the final version of the manuscript. SSC helped review the 


\section{WHAT IS ALREADY KNOWN ON THIS TOPIC}

The symptoms of coeliac disease may be insidious so delays in diagnosis are common Routine duodenal biopsy has been suggested as a way to ensure that no cases are missed at gastroscopy

\section{WHAT THIS STUDY ADDS}

Pre-endoscopy serological testing and biopsy of "high risk" cases has a 100\% sensitivity All patients referred for gastroscopy with high risk symptoms should be biopsied irrespective of their antibody profile
21 Hill ID. What are the sensitivity and specificity of serologic tests for celiac disease? Do sensitivity and specificity vary in different populations? Gastroenterology 2005;128(4 suppl 1):S25-32

22 Lock RJ, Stevens S, Pitcher MC, Unsworth DJ. Is immunoglobulin A anti-tissue transglutaminase antibody a reliable serological marker of coeliac disease? Eur J Gastroenterol Hepatol 2004;16:467-70.

23 Revised criteria for diagnosis of coeliac disease. Report of working group of European Society of Paediatric Gastroenterology and Nutrition. Arch Dis Child 1990;65:909-11.

24 National Institutes of Health Consensus Development Conference Statement on Celiac Disease, June 28-30, 2004. Gastroenterology 2005;128(4 suppl 1):S1-9.

25 Oberhuber G, Granditsch G, Vogelsang H. The histopathology of coeliac disease: time for a standardized report scheme for pathologists. Eur J Gastroenterol Hepatol 1999;11:1185-94.

histopathology, analyse and interpret the data, and review the final version of the manuscript. DSS conceived and designed the study. DSS helped recruit patients, analyse and interpret data, and review the final version of the manuscript.

Funding: None.

Competing interests: DSS is an associate medical adviser for Coeliac UK (National Medical Charity). This is an honorary post with no financial benefits. Ethical approval: South Sheffield research and ethics committee.

1 Johnston SD, Watson RG, McMillan SA, Sloan J, Love AH. Prevalence of coeliac disease in Northern Ireland. Lancet 1997;350:1370.

2 West J, Logan RF, Hill PG, Lloyd A, Lewis S, Hubbard R, et al. Seroprevalence, correlates, and characteristics of undetected coeliac disease in England. Gut 2003;52:960-5.

3 Sanders DS, Patel D, Stephenson TJ, Ward AM, McCloskey EV, Hadjivassiliou M, et al. A primary care cross-sectional study of undiagnosed adult coeliac disease. Eur / Gastroenterol Hepatol 2003;15:407-13.

4 Fasano A, Berti I, Gerarduzzi T, Not T, Colletti RB, Drago S, et al. Prevalence of celiac disease in at-risk and not-at-risk groups in the United States: a large multicenter study. Arch Intern Med 2003;163:286-92.

5 Green PH, Jabri B. Coeliac disease. Lancet 2003;362:383-91.

6 Fasano A, Catassi C. Current approaches to diagnosis and treatment of celiac disease: an evolving spectrum. Gastroenterology 2001;120:636-51.

7 Maki M, Mustalahti K, Kokkonen J, Kulmala P, Haapalahti M, Karttunen T, et al. Prevalence of celiac disease among children in Finland. N Engl J Med 2003;348:2517-24.

8 Sanders DS, Carter MJ, Hurlstone DP, Pearce A, Ward AM, McAlindon ME, et al. Association of adult coeliac disease with irritable bowel syndrome: a case-control study in patients fulfilling ROME II criteria referred to secondary care. Lancet 2001;358:1504-8.

9 Hin H, Bird G, Fisher P, Mahy N, Jewell D. Coeliac disease in primary care: case finding study. BMJ 1999;318:164-7.

10 Sanders DS, Hurlstone DP, Stokes RO, Rashid F, Milford-Ward A, Hadjivassiliou $M$, et al. Changing face of adult coeliac disease: experience of a single university hospital in South Yorkshire. Postgrad Med I 2002;78:31-3.

11 Green PHR, Stavropoulos SN, Panagi SG, Goldstein SL, McMahon DJ, Absan $\mathrm{H}$, et al. Characteristics of adult celiac disease in the USA: results of a national survey. Am J Gastroenterol 2001;96:126-31.

12 Lankisch PG, Martinez Schramm A, Petersen F, Droge M, Lehnick D, Lembcke B. Diagnostic intervals for recognizing celiac disease. $Z$ Gastroenterol 1996;34:473-7.

13 Dickey W, McConnell JB. How many hospital visits does it take before celiac sprue is diagnosed? / Clin Gastroenterol 1996;23:21-3.

14 Sanders DS, Hopper AD, Azmy IA, Rahman N, Hurlstone DP, Leeds JS, et al. Association of adult celiac disease with surgical abdominal pain: a case-control study in patients referred to secondary care. Ann Surg 2005;242:201-7.

15 Collin P, Mustalahti K, Kyronpalo S, Rasmussen M, Pehkonen E, Kaukinen K. Should we screen reflux oesophagitis patients for coeliac disease? Eur / Gastroenterol Hepatol 2004;16:917-20.

16 Cuomo A, Romano M, Rocco A, Budillon G, Del Vecchio Blanco C, Nardone G. Reflux oesophagitis in adult coeliac disease: beneficial effect of a gluten free diet. Gut 2003;52:514-7.

17 Talal AH, Murray JA, Goeken JA, Sivitz WI. Celiac disease in an adult population with insulin-dependent diabetes mellitus: use of endomysial antibody testing. Am / Gastroenterol 1997;92:1280-4.

18 Ferguson A, Arranz E, O'Mahony S. Clinical and pathological spectrum of coeliac disease-active, silent, latent, potential. Gut 1993;34:150-1.

19 Logan RF, Rifkind EA, Turner ID, Ferguson A. Mortality in celiac disease. Gastroenterology 1989;97:265-71.

20 West J, Logan RF, Smith CJ, Hubbard RB, Card TR. Malignancy and mortality in people with coeliac disease: population based cohort study. BMJ 2004;329:716-9. and re-defining. OIM 1995;88:9-13.

27 Collin P, Kaukinen K, Vogelsang H, Korponay-Szabo I, Sommer R, Schreier E, et al. Antiendomysial and antihuman recombinant tissue transglutaminase antibodies in the diagnosis of coeliac disease: a biopsy-proven European multicentre study. Eur / Gastroenterol Hepatol 2005;17:85-91.

28 Olds G, McLoughlin R, O'Morian C, Sivak MV Jr. Celiac disease for the endoscopist. Gastrointest Endosc 2002;56:407-15.

29 Van Heel DA, West J. Recent advances in coeliac disease. Gut 2006;55:1037-46.

30 Green PH, Murray JA. Routine duodenal biopsies to exclude celiac disease? Gastrointest Endosc 2003:58:92-5.

31 Brocchi E, Bonora M, Epifanio G, Tomassetti P, Biasco G Corinaldesi R. Routine duodenal biopsies: is it time to change our minds? Gastrointest Endosc 2004:59:331-2.

32 Hopper AD, Cross SS, McAlindon ME, Sanders DS. Symptomatic giardiasis without diarrhea: further evidence to support the routine duodenal biopsy? Gastrointest Endosc 2003;58:120-2.

33 Dobru D, Pascu O, Tanta M, Gheorghe C, Goldis A, Balan G, et al. The prevalence of coeliac disease at endoscopy units in Romania: routine biopsies during gastroscopy are mandatory (a multicentre study). Rom / Gastroenterol 2003;12:97-100.

34 Williams L, Dew MJ, Murray LA, Williams DW. Are routine duodenal biopsies taken at the time of an upper $\mathrm{Gl}$ endoscopy clinically useful? Gastroenterol Today 2001;11:73-6.

35 Dickey W. Diagnosis of coeliac disease at open-access endoscopy. Scand J Gastroenterol 1998;33:612-5.

36 Mahadeva S, Wyatt JI, Howdle PD. Is a raised intraepithelial lymphocyte count with normal duodenal villous architecture clinically relevant? J Clin Pathol 2002;55:424-8.

37 Dickey W, Hughes D. Prevalence of celiac disease and its endoscopic markers among patients having routine upper gastrointestinal endoscopy. Am J Gastroenterol 1999;94:2182-6.

38 Voutilainen M, Juhola M, Farkkila M, Sipponen P. Gastric metaplasia and chronic inflammation at the duodenal bulb mucosa. Dig Liver Dis 2003;35:94-8.

39 Collin P, Rasmussen M, Kyronpalo S, Laippala P, Kaukinen K. The hunt for coeliac disease in primary care. OJM 2002;95:75-7.

40 Bardella MT, Minoli G, Ravizza D, Radaelli F, Velio P, Quatrini M, et al. Increased prevalence of celiac disease in patients with dyspepsia. Arch Intern Med 2000;160:1489-91.

41 Kori M, Gladish V, Ziv-Sokolovskaya N, Huszar M, Beer-Gabel M, Reifen $\mathrm{R}$. The significance of routine duodenal biopsies in pediatric patients undergoing upper intestinal endoscopy. J Clin Gastroenterol 2003;37:39-41.

42 Lima VM, Gandolfi L, Pires JA, Pratesi R. Prevalence of celiac disease in dyspeptic patients. Arq Gastroenterol 2005;42:153-6.

43 Goddard AF, McIntyre AS, Scott BB. Guidelines for the management of iron deficiency anaemia. British Society of Gastroenterology. Gut 2000;46(suppl 3-4):IV1-5.

44 Thomas PD, Forbes A, Green J, Howdle P, Long R, Playford R, et al. Guidelines for the investigation of chronic diarrhoea, 2nd edition. Gut 2003;52(suppl 5):v1-15.

45 Feighery C, Weir DG, Whelan A, Willoughby R, Youngprapakorn S, Lynch S, et al. Diagnosis of gluten-sensitive enteropathy: is exclusive reliance on histology appropriate? Eur J Gastroenterol Hepatol 1998;10:919-25.

46 Shidrawi RG, Przemioslo R, Davies DR, Tighe MR, Ciclitira PJ. Pitfalls in diagnosing coeliac disease. J Clin Pathol 1994;47:693-4.

47 Hill PG, McMillan SA. Anti-tissue transglutaminase antibodies and their role in the investigation of coeliac disease. Ann Clin Biochem 2006;43(Pt 2):105-17.

48 Korponay-Szabo IR, Raivio T, Laurila K, Opre J, Kiraly R, Kovacs JB, et al. Coeliac disease case finding and diet monitoring by point-ofcare testing. Aliment Pharmacol Ther 2005;22:729-37.

49 Nemec G, Ventura A, Stefano M, Leo GD, Baldas V, Tommasini A et al. Looking for celiac disease: diagnostic accuracy of two rapid commercial assays. Am J Gastroenterol 2006;101:1597-600.

Accepted: 30 January 2007 